\title{
Design of a fuzzy differential evolution algorithm to predict non-deposition sediment transport
}

\author{
Isa Ebtehaj $^{1} \cdot$ Hossein Bonakdari $^{1}$ (I)
}

Received: 13 January 2017/Accepted: 10 April 2017/Published online: 18 April 2017

(C) The Author(s) 2017. This article is an open access publication

\begin{abstract}
Since the flow entering a sewer contains solid matter, deposition at the bottom of the channel is inevitable. It is difficult to understand the complex, three-dimensional mechanism of sediment transport in sewer pipelines. Therefore, a method to estimate the limiting velocity is necessary for optimal designs. Due to the inability of gradient-based algorithms to train Adaptive Neuro-Fuzzy Inference Systems (ANFIS) for non-deposition sediment transport prediction, a new hybrid ANFIS method based on a differential evolutionary algorithm (ANFIS-DE) is developed. The training and testing performance of ANFIS-DE is evaluated using a wide range of dimensionless parameters gathered from the literature. The input combination used to estimate the densimetric Froude number $(F r)$ parameters includes the volumetric sediment concentration $\left(C_{V}\right)$, ratio of median particle diameter to hydraulic radius $(d / R)$, ratio of median particle diameter to pipe diameter $(d / D)$ and overall friction factor of sediment $\left(\lambda_{s}\right)$. The testing results are compared with the ANFIS model and regression-based equation results. The ANFISDE technique predicted sediment transport at limit of deposition with lower root mean square error $(\mathrm{RMSE}=0.323)$ and mean absolute percentage of error $(\mathrm{MAPE}=0.065)$ and higher accuracy $\left(R^{2}=0.965\right)$ than the ANFIS model and regression-based equations.
\end{abstract}

Keywords ANFIS · Bed load · Differential Evolution (DE) $\cdot$ Non-deposition $\cdot$ Pipe $\cdot$ Sediment transport

Hossein Bonakdari

bonakdari@yahoo.com

1 Department of Civil Engineering, Razi University, Kermanshah, Iran

\section{Introduction}

A significant concern regarding sediment transport with inflow is solid matter deposition in the pipe channel. It is essential to determine the limiting velocity (at a constant slope) in dry weather flow (DWF) for sediment transport without deposition. Moreover, the pipe diameter should be sufficiently capable of transporting maximum flow in wet weather flow (WWF). Sedimentation can increase the bed roughness and decrease the cross-sectional area of the channel. The long-term accumulation of sediment on the bed can increase the risk of stabilization and cementation, thus causing transport capacity reduction. Therefore, a criterion for predicting the limiting velocity to prevent sediment deposition is essential.

The simplest traditional method is to use a constant limiting velocity value provided in many references for different hydraulic and geographical situations (see more details in Ebtehaj et al. 2014). This method is inaccurate in some circumstances because the values do not consider hydraulic and sediment characteristics, such as pipe diameter, flow depth, hydraulic radius, median particle diameter and volumetric sediment concentration.

Numerous experimental and analytical studies have been done to identify which parameters influence sediment transport (Mayerle et al. 1991; Nalluri and Ab Ghani 1996; May 2003; Banasiak 2008; Vongvisessomjai et al. 2010; Almedeij 2012; Bonakdari and Ebtehaj 2014a). These studies yielded various equations for determining the limiting velocity. The presented equations fall in two groups: (i) semi-experimental equations derived from solving the force acting on equilibrium and (ii) dimensional analysisbased equations. May et al. (1996) used 7 different datasets (Ackers et al. 1996) in 332 tests and presented a semiexperimental relationship in the form of Eq. (1). It is 
recognized as the best semi-experimental equation for nondeposition sediment transport (Vongvisessomjai et al. 2010; Ebtehaj and Bonakdari 2014a):

$$
\begin{aligned}
C_{V}= & 3.03 \\
& \times 10^{-2}\left(\frac{D^{2}}{A}\right)\left(\frac{d}{D}\right)^{0.6}\left(\frac{V^{2}}{g(s-1) D}\right)^{1.5}\left(1-\frac{V_{t}}{V}\right)^{4}
\end{aligned}
$$

$V_{t}=0.125 \sqrt{g(s-1) d}\left(\frac{y}{d}\right)^{0.47}$,

where $C_{V}$ is the volumetric sediment concentration, $D$ is the pipe diameter, $d$ is the median particle diameter, $V$ is the flow velocity, $V_{t}$ is the incipient motion velocity of sediment (Eq. 2), $A$ is the cross-sectional area of the flow, $g$ is the gravitational acceleration, $s\left(=\rho_{s} / \rho\right)$ is the specific gravity of sediment and $y$ is the flow depth.

Ebtehaj et al. (2014) presented a regression-based equation to determine the densimetric Froude number $(\mathrm{Fr})$ by dimensional analysis with a wide range of data as follows:

$F r=\frac{V}{\sqrt{g(s-1) d}}=4.49 C_{V}^{0.21}\left(\frac{d}{R}\right)^{-0.54}$.

The lack of knowledge and complexity of flow conditions have led to uncertainty modeling. Due to the innate uncertainty and insufficient accuracy of regression-based equations, such equations do not perform well in some hydraulic circumstances. Therefore, utilizing this method leads to overestimated or underestimated plans (Bonakdari and Ebtehaj 2014b).

Because artificial intelligence (AI) performs adequately (Gholami et al. 2011; Al-Abadi 2014; Gorai et al. 2014; Mondal et al. 2015), techniques such as neural networks (Ebtehaj and Bonakdari 2013), decision trees (Ivanovich and Hamid 2014), fuzzy logic (Demirci and Baltaci 2013), evolutionary computing (Ebtehaj and Bonakdari 2016), and gene expression programming (Ab Ghani and Azamathulla 2014) have been successfully applied in sediment transport modeling. Shoorehdeli et al. (2007) developed a new hybrid particle swarm optimization (PSO) algorithm for ANFIS network training. The authors modified the PSO for the training scheme in the antecedent part of the fuzzy rules, inspired by the genetic algorithm and using adaptive weighted by PSO. They demonstrated that the new ANFIS is less complex and more accurate than the gradient-based method in ANFIS training.

Moosavi et al. (2013) applied hybrid models based on Wavelet, Wavelet-ANFIS and Wavelet-ANN for groundwater level forecasting during different prediction periods. The results of ANFIS, Wavelet-ANFIS, ANN and Wavelet-ANN indicated that the hybrid methods exhibit superior precision to both ANFIS and ANN, while Wavelet-ANFIS performs the best of all models. Ebtehaj and Bonakdari (2014b) optimized the MLP-ANN weights in sediment transport prediction using two evolutionary algorithms (EA): the imperialist competitive algorithm (ICA) and genetic algorithm (GA). A comparison of the hybrid methods (ANN-ICA and ANN-GA) with the general ANN indicated that EA performs significantly better than ANN.

Ebtehaj and Bonakdari (2014a) evaluated the ANFIS performance in predicting sediment transport. The authors recommended applying evolutionary algorithms for the optimum selection of ANFIS membership functions. Therefore, in this study, ANFIS is coupled with the DE algorithm for the first time to develop a hybrid model and assess sediment transport in sewers. The main goal is to increase prediction accuracy and reliability by benefiting from the specific nature of each approach. The DE algorithm is applied to optimize the membership function of the ANFIS network using three datasets with a wide range of data. The parameters affecting limiting velocity (i.e. $\mathrm{Fr}$ ) prediction are identified initially by examining the influential factors on sediment transport. Thereafter, six models are proposed to assess the effect of different parameters on $\mathrm{Fr}$ prediction. The developed ANFISDE model predictions are compared with the ANFIS model as well as existing sediment transport equations.

\section{Theoretical background of the method used}

\section{Overview of ANFIS}

Adaptive neuro-fuzzy inference systems (ANFIS) (Jang et al. 1997) are a hybrid soft computing (SC) technique where artificial neural networks (ANN) are combined with fuzzy logic (FL). The fuzzy membership values are obtained through ANN training (Bui et al. 2017a). This method's process entails rapid convergence and high accuracy. A fuzzy inference system (FIS) with two inputs ( $x$ and $y$ ) and $f$ as an output is an example of this process. For sediment transport in pipe channels, the $x$ and $y$ parameters are considered the volumetric sediment concentration $\left(C_{V}\right)$ and a dimensionless parameter (the ratio of hydraulic radius to median particle diameter $d / R$ ). Moreover, $F$ as an output parameter represents the $F r$ function. This example is examined for two input parameters. For a first-order Takagi-Sugeno fuzzy model, it is possible to set a sample rule with two IF-THEN rules as follows:

Rule 1 : IF $x=A_{1}, y=B_{1}$ THEN $f_{1}=p_{1} x+q_{1} y+r_{1}$

Rule 1 : IF $x=A_{2}, y=B_{2}$ THEN $f_{1}=p_{2} x+q_{2} y+r_{2}$.

The antecedent part (IF) and consequent part (THEN) of a fuzzy rule are fuzzy in nature and the crisp function of the 
variable is a linear equation or rule (respectively). If $C_{V}$ and $d / R$ are considered $F r$ model input variables, Eqs. 1 and 2 can be rearranged as follows:

$$
\begin{gathered}
\text { Rule } 1 \text { : IF } C_{V} \text { is LOW and }(d / R) \text { is LOW, THEN } F r \\
=p_{1} C_{V}+q_{1}(d / R)+r_{1}
\end{gathered}
$$

Rule 1 : IF $C_{V}$ is HIGH and $(d / R)$ is Medium, THEN $F r$

$$
=p_{2} C_{V}+q_{2}(d / R)+r_{2} \text {, }
$$

where $p_{i}, q_{i}$ and $r_{i}(i=1,2,3, \ldots, n)$ are the set of parameters. Figure 1 presents the overall structure of ANFIS with two inputs and ANFIS with four inputs used in this study. The performance of the different layers shown in this figure is as follows:

First layer Each node in this layer produces the membership degree from an input variable.

$O_{i}^{1}=\mu_{A_{i}}\left(C_{V}\right) \quad i=1,2$,

where $C_{V}$ is the input of the $i$ th node and $A_{i}$ is the linguistic label related to this node's function. For $d / R$ (the second input parameter), another function can be derived as in Eq. 9:

$O_{i}^{1}=\mu_{B_{i-2}}(d / R) \quad i=3,4$.

$O_{i}^{1}$ is regarded as the membership function $A_{i}(\mathrm{MF})$ and it determines the degree that satisfies a given input $\left(C_{V}\right.$ or $d /$ $R$ ) to the $A_{i}$ quantity. These functions are smooth and have concise notation; for this reason, the most accepted membership functions in ANFIS are deemed to be the Gaussian and bell shape functions (Bui et al. 2012). Both have the advantages of smoothness and being non-zero at all points. The bell shape MF (Eq. 10) has a greater parameter than the Gaussian MF (Eq. 11); as a result, it can approach the non-fuzzy set if the free parameter is tuned (MATLAB and Statistics Toolbox Release 2009). Therefore, the Gaussian MF is employed in this study.

$A_{i}\left(C_{V}\right)=\frac{1}{1+\left[\left(C_{V}-C_{i}\right) / a_{i}\right]^{2 b_{i}}}$

$A_{i}\left(C_{V}\right)=\exp \left(-\frac{\left\|C_{V}-c_{i}\right\|^{2}}{2 \sigma_{i}^{2}}\right)$,

where $\left\{a_{i}, b_{i}, c_{i}\right.$ and $\left.\sigma_{i}\right\}$ is the parameter set of Gaussian MFs and $\mu$ is the MF of $A_{i}$. Changing any of the parameters leads to different MF results. Hence, representing different forms of MFs is dependent on the linguistic label $A_{i}$. In fact, many of the piecewise and continuous functions in this node may be used. The parameters of this layer are introduced as premise parameters. Three membership functions are derived for each input model presented in Fig. 2.

Second layer This layer consists of circular nodes marked with П. The following equation is multiplied by the input signal and these nodes are sent to the output produced:

$O_{i}^{2}=w_{i}=A_{i}\left(C_{V}\right) B_{i}(d / R) \quad i=1,2$.

Each node's output indicates the firing strength of a specified rule.

Third layer Here, circular nodes (Ns) calculate the ratio of the firing strength rule (ith rule) to the sum of all firing strength rules, as follows:

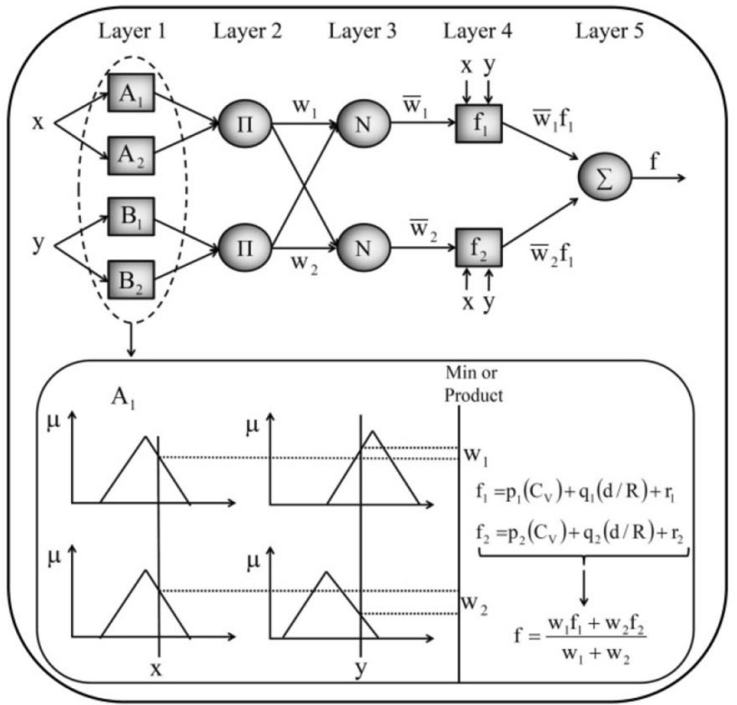

Fig. 1 ANFIS structures (general and quadruple)

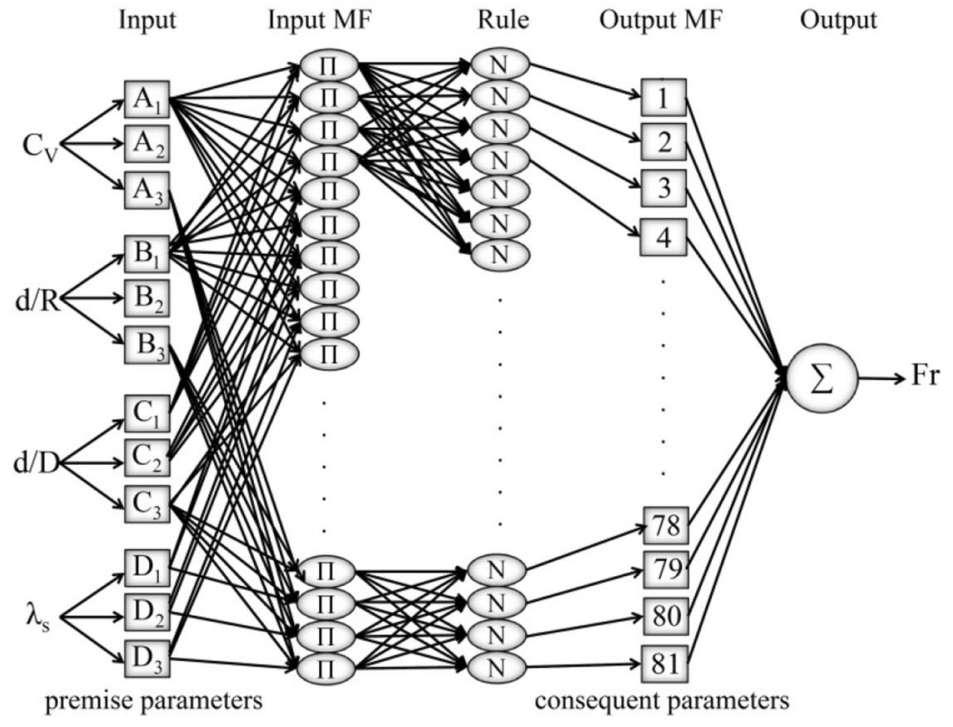

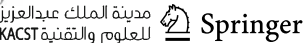



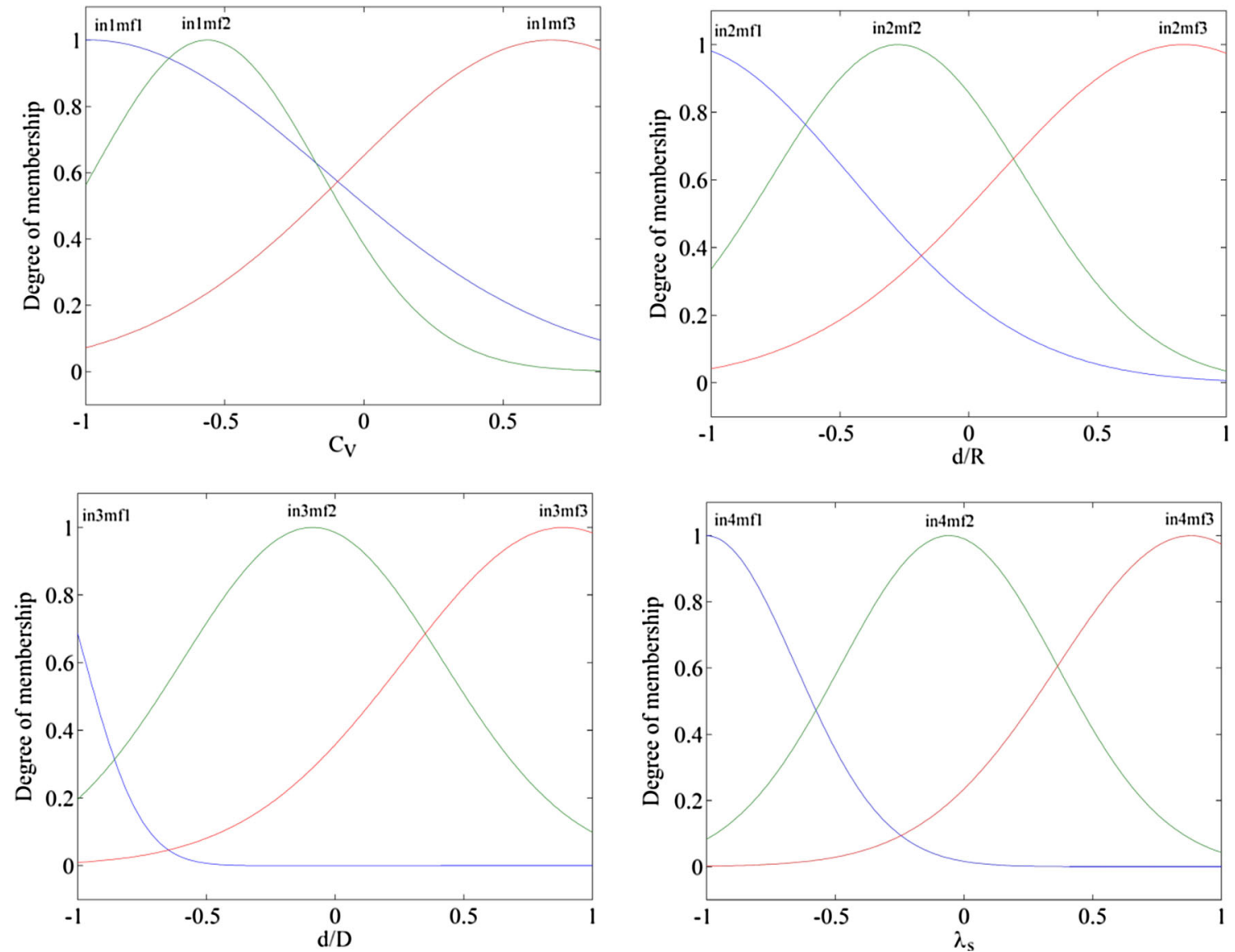

Fig. 2 Fuzzy membership functions for the input parameters

$O_{i}^{3}=\bar{w}_{i}=\frac{w_{1}}{w_{1}+w_{2}}, \quad i=1,2$

This layer's output is presented as the normalized firing strength.

Fourth layer The parameter values of $p, q$ and $r$ are optimized in this layer. All nodes in this layer adapt to a node function as follows:

$O_{i}^{4}=\bar{w}_{i}\left(p_{i} C_{V}+q_{i}(d / R)+r_{i}\right)$,

where $\left\{p_{i}, q_{i}, r_{i}\right\}$ is the parameter set and $\bar{w}$ is the normalized weight. The parameters in this layer are known as consequent parameters.

Fifth layer The circular single node in this layer, $\Sigma$, and all outputs are calculated as the sum of all input signals as:

$O_{i}^{5}=\sum \bar{w}_{i} f_{i}=\frac{\sum w_{i} f_{i}}{\sum w_{i}}$.

ANFIS is trained using backpropagation and a hybrid of backpropagation with least squares. Hence, the hybrid method employs backpropagation for input data (premise parameters) and least squares for output MFs (consequent parameters).
Ebtehaj and Bonakdari (2014a) showed that the hybrid algorithm presents better results than backpropagation. Hence, this algorithm is employed in the present study to estimate $F r$ with the ANFIS network. In addition to these algorithms, the more recent use of hybrid ANFIS has led to improved ANFIS prediction results (Cus et al. 2009; Shoorehdeli et al. 2009; Chang et al. 2011; Chen 2013; Bui et al. 2016a, 2017b). Therefore, Differential Evolution (DE) is employed in this study and the results are compared with the hybrid algorithm results.

\section{Differential evolution}

Differential evolution (DE) is a powerful evolutionary global optimization method that was proposed by Storn and Price (1997). The advantages of DE are its simple structure, quality of solutions found, and ease of implementation (Liu and Lampinen 2002; Bui et al. 2016b). Thus, it has been applied in many different practical cases. EA is grouped as an optimization stochastic algorithm and is inspired by biological processes, whereby survival of the 
fittest is required for compliance with environmental and inherent genetic features (Bäck et al. 1997).

If the objective functions to be optimized and named are $f$, we have:

$f(V): R^{D} \rightarrow R$

where $R$ is related to real data and $D$ represents the objective function parameters $f(V)$. The DE algorithm aims to minimize the objective function using the optimized parameter values:

$V=\left(v_{1}, \ldots, v_{D}\right), \quad V \in R^{D}$,

where $V$ is a vector including the parameters of the objective function of $D$. The objective function is the mean squared error between the actual and estimated $F r$. The objective function parameters are defined as follows:

$v_{i}^{(\mathrm{L})} \leq v_{i} \leq v_{i}^{(\mathrm{U})}$,

where $v_{i}^{(\mathrm{L})}$ and $v_{i}^{(\mathrm{U})}$ are related to the lower and upper boundaries, respectively.

Like other evolutionary algorithms, DE acts on a population $\left(P_{G}\right)$ of candidate solutions and not only on a single solution. If $G$ is considered the generation of a population, the population evaluated by $\mathrm{DE}$ can be stated as follows:

$P_{G}=\left(v_{1, G}, v_{2, G}, \ldots, V_{\mathrm{NP}, G}\right) G=0, \ldots, G_{\max }$,

where $G_{\max }$ is the maximum generation that usually serves as the stopping criterion of DE (Bui et al. 2016b). Each vector contains the exact parameter of $D$ considered an individual chromosome.

$v_{i, G}=\left(v_{1, i, G}, v_{2, i, G}, \ldots, V_{D, i, G}\right) \quad i=1,2, \ldots, \mathrm{NP}$

$G=0, \ldots, G_{\max }$.

An initial population should be created to establish a starting point for the optimal search. In general, there is no information about the optimal solutions except the optimum problem parameters. Therefore, one of the methods to determine the initial population, $P_{G}=0$, is the random selection of restrictions given as follows:

$v_{j, i, 0}=\operatorname{rand}_{j}[0,1]\left(v_{j}^{(U)}-v_{j}^{(L)}\right)+v_{j}^{(L)} \quad i=1,2, \ldots, \mathrm{NP}$

$j=1,2, \ldots, D$,

where $\operatorname{rand}_{j}[0,1]$ is a random value distributed consistently in the $[0,1]$ range, which is selected for every new $j$. The DE procedure differs from other evolutionary algorithms. From the primary production to the regular population of vectors, $P_{G}$ is combined and sampled randomly to produce candidate vectors for the next generation, $P_{G+1}$.

A candidate population of vectors obtained from different trials, $P_{G+1}^{/}=U^{i G+1}=u_{j}, I, G+1$, is calculated as follows: $u_{j, i, G+1}=\left\{\left\{\begin{array}{c}v_{j, r 3, G}+F\left(v_{j, r 1, G}-v_{j, r 2, G}\right) \text { if } v_{j}^{(\mathrm{L})}<y_{j, i, G+1}<v_{j}^{(\mathrm{U})} \\ \text { otherwise and }[0,1]\left(v_{j}^{(\mathrm{U})}-v_{j}^{(\mathrm{L})}\right)+v_{j}^{(\mathrm{L})} \\ \text { otherwise } v_{j, i, G}\end{array}\right\}\right.$

where $r_{1}, r_{2}$ and $r_{3}$ are values that differ in each run and $i$ is a parameter whose value should be specified. The correct values of parameters $r_{1}, r_{2}$ and $r_{3}$ are randomly selected for each $i$ value.

The next generation population, $P_{G+1}$, is selected from the current population $\left(P_{G}\right)$ and the population of children follows this equation:

$V_{i, G+1}=\left\{\begin{array}{rr}U_{i, G+1} & \text { if } f\left(U_{i, G+1}\right) \leq\left(V_{i, G}\right) \\ V_{i, G} \text { otherwise }\end{array}\right\}$

Thus, the temporary population of individuals is compared with their peers' population. Assuming the objective function is minimized, the vector with the lowest objective function value gains a new position in the next generation. As a result, every individual from the next population is good or better than peers from the general population.

\section{Statistical measure}

To evaluate the performance of each method, the following statistical indicators are calculated: the coefficient of determination $\left(R^{2}\right)$, Root Mean Squared Error (RMSE), Mean Absolute Error (MAE), Mean Absolute Relative Error (MARE) and average absolute deviation $(\delta)$.

$R^{2}=1-\frac{\sum_{i=1}^{n}\left(O_{i}-t_{i}\right)^{2}}{\sum_{i=1}^{n}\left(O_{i}-\bar{O}_{i}\right)^{2}}$

$\mathrm{RMSE}=\sqrt{\frac{1}{n} \sum_{i=1}^{n}\left(O_{i}-t_{i}\right)^{2}}$

MAE $=\frac{1}{n} \sum_{i=1}^{n}\left|O_{i}-t_{i}\right|$

MARE $=\frac{1}{n} \sum_{i=1}^{n} \frac{\left|O_{i}-t_{i}\right|}{O_{i}}$

$\delta=\frac{\sum_{i=1}^{n}\left|O_{i}-t_{i}\right|}{\sum_{i=1}^{n} O_{i}}$.

\section{Methodology}

Experimental and analytical studies of sediment transport in pipe channels indicate the effects of the hydraulic parameters of flow and sediment characteristics on the velocity of flow. Therefore, to determine the limiting 
velocity that would prevent solids from settling on the channel bed, a functional relationship is given as follows:

$V=f\left(R, y, d, C_{V}, A, g, \rho, \rho_{s} \lambda_{s}\right)$.

To estimate the limiting velocity parameters, the dimensionless parameters should be defined. Several studies in this field (Ab Ghani 1993; Vongvisessomjai et al. 2010; Azamathulla et al. 2012; Ebtehaj and Bonakdari 2013) presented the influential parameters on sediment transport in non-deposition state as follows:

$$
\begin{aligned}
F r & =V / \sqrt{g(s-1) d} \\
& =f\left(C_{V}, D_{\mathrm{gr}}, d / D, d / R, R / D, D^{2} / A, \lambda_{s}\right),
\end{aligned}
$$

where $R$ is the hydraulic radius, $y$ is the flow depth, $d$ is the median particle diameter, $C_{V}$ is the volumetric sediment concentration, $A$ is the cross-sectional area of the flow, $g$ is the gravitational acceleration, $\rho$ is the water density, $\rho_{s}$ is the sediment density, $\lambda_{s}$ is the overall friction factor of sediment, $\mathrm{Fr}$ is the densimetric Froude number, $s$ is the specific gravity of sediment $\left(=\rho / \rho_{s}\right), D_{\mathrm{gr}}\left(=d\left(g(s-1) / v^{2}\right)^{l /}\right.$ ${ }^{3}$ ) is the dimensionless particle number and $D$ is the pipe diameter.

In some recent studies, Ebtehaj and Bonakdari (2013; 2014a; 2014b; 2016) classified the dimensionless parameters presented in the above equation with respect to the nature of each parameter in the dimensionless groups of transport $\left(C_{V}\right)$, transport mode $\left(d / R, D^{2} / A\right.$ and $\left.R / D\right)$, flow resistance $\left(\lambda_{s}\right)$, movement $(F r)$ and sediment $\left(D_{\mathrm{gr}}\right.$ and $\left.d / D\right)$.

Thus, the $F r$ parameter is the target selected to estimate the limiting velocity parameter. By considering the effect of each of the following categories, four inputs are derived for the models. The inputs obtained from "transport "and "flow resistance" are constant, while "sediment" and "transport mode" have more than one parameter. Hence, different models are presented to investigate the effect of each parameter, as follows:

Model $1: F r=f\left(C_{V}, D_{g r}, d / R, \lambda_{s}\right)$

Model $2: F r=f\left(C_{V}, D_{g r}, D^{2} / A, \lambda_{s}\right)$

Model $3: F r=f\left(C_{V}, D_{g r}, R / D, \lambda_{s}\right)$

Model $4: F r=f\left(C_{V}, d / D, d / R, \lambda_{s}\right)$

Model $5: F r=f\left(C_{V}, d / D, D^{2} / A, \lambda_{s}\right)$

Model $6: F r=f\left(C_{V}, d / D, R / D, \lambda_{s}\right)$,

\section{The study site and data used}

In this study, three datasets are used to predict sediment transport in the non-deposition condition in pipe channels (Ab Ghani 1993; Ota and Nalluri 1999 and Vongvisessomjai et al. 2010). The data employed in this study are all associated with non-deposition in different hydraulic conditions, such as pipe diameter, channel slope, particle size and channel length. Details of the datasets are provided in studies carried out by Ebtehaj et al. (2014) and Ebtehaj and Bonakdari $(2014 \mathrm{a}, \mathrm{b}($. The samples are in the following ranges: $1<C_{V} \quad(\mathrm{ppm})<1280 ; 0.005<R \quad(\mathrm{~m})<0.136$; $0.013<\lambda_{s}<0.053 ; \quad 0.1<D<0.45 ; \quad 0.237<V \quad(\mathrm{~m} /$ s) $<1.216 ; 0.072<d(\mathrm{~mm})<8.3 ; 0.153<y / D<0.84$ and $5.06<D_{\mathrm{gr}}<142$.

\section{Proposed hybrid method for non-deposition sediment transport prediction}

This section describes the hybrid comprising ANFIS and a global optimization method, i.e. Differential Evolution (ANFIS-DE). ANFIS-DE is used for modeling sediment transport at limit of deposition in sewer networks. The proposed ANFIS-DE is encoded in MATLAB Environmental. First, an initial ANFIS model is produced for the sediment transport data using the training dataset. Subsequently, DE is utilized to optimize the premise and consequent parameters of the model. Once the optimum parameter values are determined, the ANFIS-DE regression model is acquired and it can be used to predict the limiting velocity for non-deposition sediment transport in sewer systems.

\section{Data preparation}

The data utilized in this study are arranged as four inputs and one output parameter $(F r)$. To present a useful predictive model with scientific significance, model validation is essential in the analysis. Therefore, all datasets collected from the literature are divided in two subsets at a ratio of 70-30 for training and testing. The training dataset comprised 150 samples that were selected randomly, whereas the rest of the samples (68) were utilized for testing to confirm the prediction accuracy of the proposed model.

\section{Model configuration}

The values of the antecedent and consequent parameters related to the initial model generated with the training dataset are not optimized. In this study, the grid partitioning method is employed for Fuzzy Inference System (FIS) generation (Ebtehaj and Bonakdari 2014a). Moreover, there are 3 MFs for each input. The MFs were selected by trial and error between the objective function values of the ANFIS-DE model vs. the number of MFs. The best antecedent and consequent parameter values related to the rules are attained in the optimization process. The parameter values are presented in Table 1. 
Table 1 DE control parameters

\begin{tabular}{lll}
\hline Number of dimensions & $D$ & 4 \\
\hline Population size & $\mathrm{NP}$ & 20 \\
Mutation constant & $\mathrm{F}$ & 0.5 \\
Crossover constant & $\mathrm{CR}$ & 0.9 \\
parameters; boundaries & $V_{j}^{(\mathrm{U})}$ & 12 \\
$(j=1, \ldots, 4)$ & $V_{j}^{(\mathrm{L})}$ & -12 \\
\hline
\end{tabular}

\section{ANFIS model training using PSO}

The structure of the proposed hybrid ANFIS-DE for sediment transport modeling is illustrated in Fig. 3. The network training process is defined by having to reach the convergence criterion and continuing until the number of iterations or objective functions determined is reached. The DE algorithm selection process is as follows:

First, to avoid expansion process duplication, the values of the objective function and constraint functions for parameter $V_{i, G}$ are stored in the variables. $U_{i, G+1}$ refuses constraint function values greater than the $V_{i, G}$ value and rejects these constraint functions without reassessment. If $V_{i, G}$ is not convinced of all constraints, $U_{i, G+1}$ probing is done because the constraint is still much less than $V_{i, G}$. As the $U_{i, G+1}$ and $V_{i, G}$ values are searched, the membership function to probe the new $U_{G+1}$ should be evaluated. This practice continues until the value of $U_{i, G}+1$ becomes greater than $V_{i, G}$. In this case, the membership function value is not evaluated once more.

\section{Stopping criteria}

The maximum number of iterations and minimum defined error are utilized as stopping criteria, such that if one of the conditions is satisfied the optimization process in terminated. In this case, the objective function defined as RMSE (Eq. 25) is the smallest and the antecedent and consequent parameters are assigned to the ANFIS-DE model. The validation dataset is employed to validate the final model for accuracy and to predict the limiting velocity required to prevent sedimentation in sewer systems.

\section{Results and discussion}

The results of the Artificial Intelligence methods (ANFIS and ANFIS-DE) and regression equations in predicting sediment transport at limit of deposition in sewer systems are presented in this section. Figure 4 shows the results of $\mathrm{Fr}$ estimation using the ANFIS and ANFIS-DE methods. Model 1 that employs $C_{V}, D_{\mathrm{gr}}, d / R$ and $\lambda_{s}$ as inputs produced good results with both methods. $F r$ estimated by
ANFIS-DE mostly had less than $10 \%$ relative error. According to Table 2, the average relative error of Model 1 for all samples in testing mode was about $8 \%$ $($ MARE $=0.076)$, but with ANFIS it was often more than $10 \%$. The estimates were both under and overestimates $($ MARE $=0.099)$. Other indicators presented in the table also indicate the superiority of ANFIS-DE over ANFIS. Therefore, the DE evolutionary algorithm in Model 1 outperformed the hybrid algorithm (backpropagation with least squares).

In Models 1, 2 and 3, the influence of parameters related to the transport mode $\left(d / R, D^{2} / A \& R / D\right)$ is examined. By applying the constant parameters of sediment $\left(D_{\mathrm{gr}}\right)$, transport $\left(C_{V}\right)$ and flow resistance $\left(\lambda_{s}\right)$, besides using parameter $D^{2} / A$ instead of $d / R$ (Model 2 ), the performance of both methods significantly decreased compared with Model 1 . The statistical indices show that the relative error in estimating $\mathrm{Fr}$ reached over 20\% (MARE for ANFIS $=0.24$; MARE for ANFIS-DE $=0.232$ ) and the RMSE of both methods was double that for Model 1. In this model, most estimations were considered underestimations, and using its results would lead to excessive solid deposition on the channel bed and reduced transmission capacity. Therefore, using $D^{2} / A$ as a transport mode parameter in addition to $C_{V}$, $D_{\mathrm{gr}}$, and $\lambda_{s}$ has a negative impact on ANFIS and ANFISDE performance in predicting the limiting velocity $(F r)$. This resulted in high error values, low accuracy $\left(R^{2}\right.$ for ANFIS $=061$ and $R^{2}$ for ANFIS-DE $\left.=0.72\right)$ and high sediment deposition.

Based on the statistical indices presented in Table 2 and the scatter plot in Fig. 4, Model 3 outperformed Model 2 but was inferior to Model 1. ANFIS-DE estimated Model 3 with fairly good accuracy, whereby the relative error decreased from 24\% in Model 2 to about 13\% in Model 3. However, Model 3 still made underestimations. The $\mathrm{Fr}$ predicted by ANFIS and the input combination of Model 3 that employed $R / D$ as a transport mode parameter led to a decrease in relative error by 3\% compared with Model 2 . Hence, the $F r$ value had high relative error and was underestimated. Models 2 and 3 were relatively similar in accuracy. Model 3 had only 4\% relative error, which was lower than Model 2, but it had a mean relative error of over $20 \%$. Consequently, using Model 3 is not reliable, as the results would decrease sediment transport capacity and increase sedimentation on the bed channel. The results obtained for Models 1, 2 and 3 signify that considering $\lambda_{s}$, $D_{\mathrm{gr}}$ and $C_{V}$ as part of the "flow resistance," "sediment" and "transport" groups (respectively) led to the best performance of ANFIS and ANFIS-DE when employing $d / R$ as a "transport mode" parameter.

Regarding Models 4-6, the influence of the transport mode group parameters was investigated when $d / D$ was used as a dimensionless parameter from the "sediment" 




Fig. 3 Flowchart of proposed method (ANFIS-DE)

group in this study. Model 4 produced good results with both methods: ANFIS $\left(R^{2}=0.929 ; \quad\right.$ RMSE $=0.452$; MAE $=0.385 ; \quad$ MARE $=0.091$ and $\delta=0.088)$ and ANFIS-DE $\left(R^{2}=0.965\right.$; RMSE $=0.323$; $\mathrm{MAE}=0.281$; MARE $=0.065$ and $\delta=0.064$ ), whereby most $F r$ predictions had less than $10 \%$ relative error. The difference between Models 1 and 4 is in their input combinations, as their parameters from the "sediment" group are $D_{\text {gr }}$ and $d /$ $D$ and the other parameters are the same. A general comparison of these models demonstrate their high accuracy. Both ANFIS and ANFIS-DE methods in Model 4 estimate with less than $10 \%$ relative error, but ANFIS showed an insignificantly greater relative error. A quantitative comparison of these models indicates that using $d / D$ in Model 4 rather than $D_{\mathrm{gr}}$ in Model 1 decreased the relative error about 1.1 and $0.8 \%$ for ANFIS-DE and ANFIS, respectively. Models 5 and 2 were compared to survey the effect of the "sediment" parameters $\left(D_{\mathrm{gr}}\right.$ and $\left.d / D\right)$ and $D^{2} / A$ as a "transport mode" parameter. It was found that Model 5 had nearly the same conditions as Model 2 and often underestimated but had a lower relative error. Consequently, the mean error of ANFIS-DE and ANFIS decreased from 24 to $18 \%$ and 23 to $16 \%$, respectively. Evidently, the simultaneously use of $d / D$ and $D^{2} / A$ may decrease the lack of effect of $d / R$ as an input on limiting velocity estimation.

By ANFIS-DE, for input combination presented in the form of Model 6 reasonable results were obtained. However, this model had significant error of over $10 \%$ as overestimation and underestimation, which would reduce its reliability and lead to uneconomical plans or sedimentation, respectively. Using ANFIS to estimate $\mathrm{Fr}$ with the input combination of Model 6 presented weaker results than ANFIS-DE, with about $15 \%$ error. A comparison of Models 6 and 3 shows that the simultaneously use of of $d / D$ and $R / D$ has insignificant impact in comparison with $D_{\mathrm{gr}}$ and $R / D$ because the $D_{\mathrm{gr}}$ is a function of $d$ as well $d / D$. In addition, the $D$ is absent in $D_{\mathrm{gr}}$ but is considered in $R / D$ in both models. 
Model 1

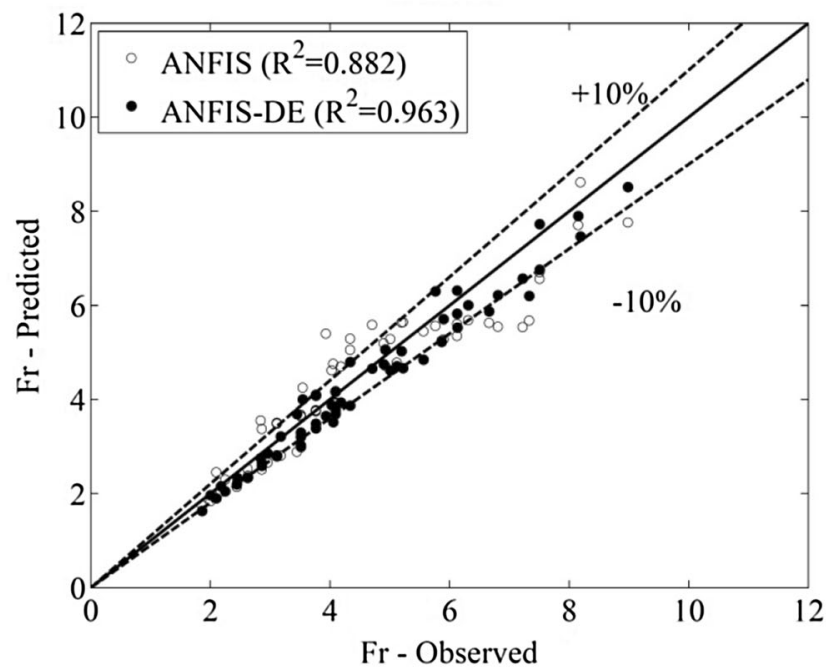

Model 3

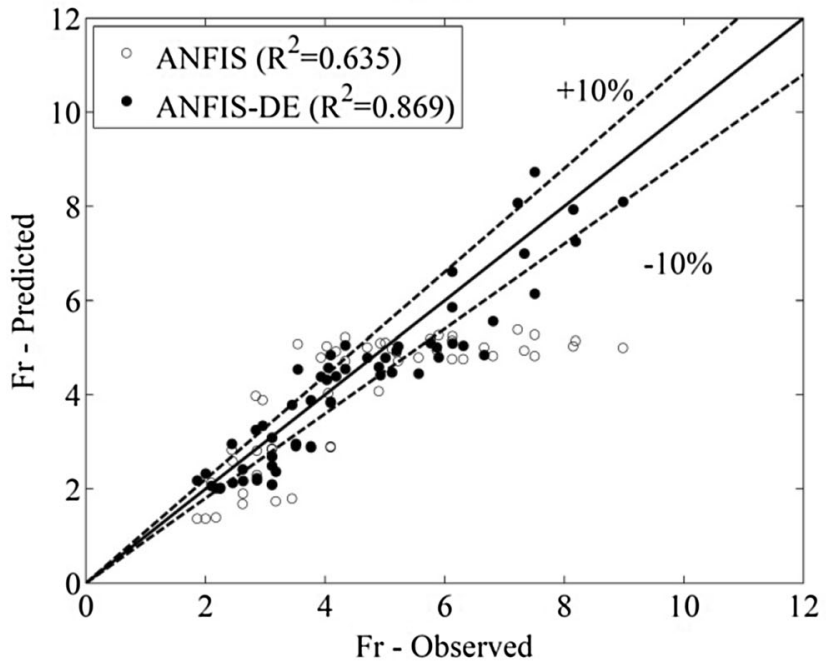

Model 5

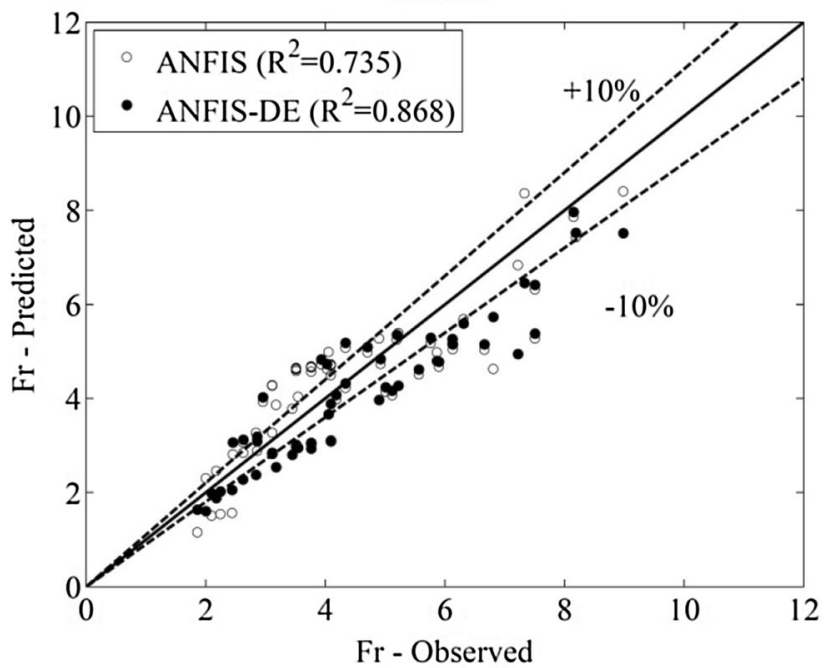

Model 2

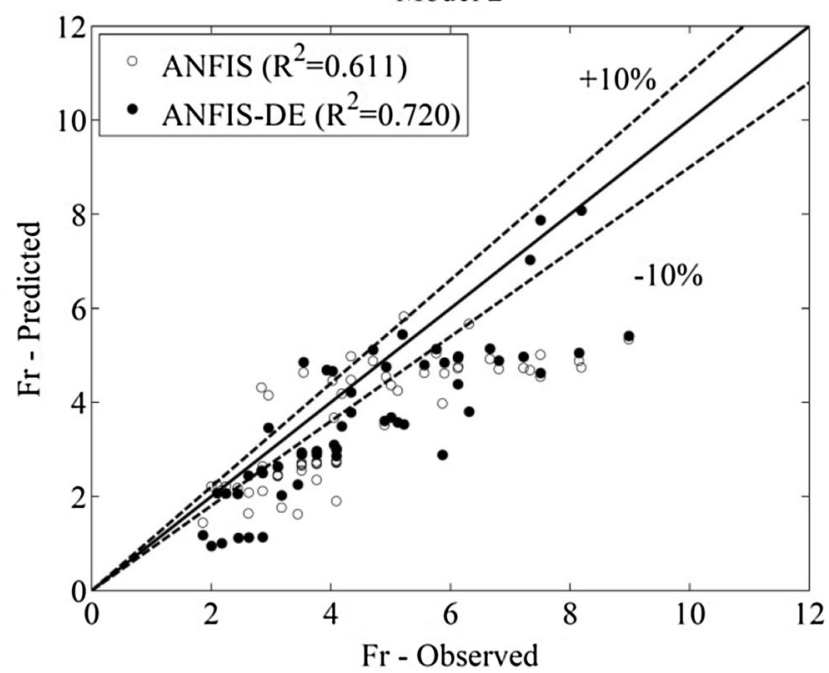

Model 4



Model 6



Fig. 4 Scatter plot of $F r$ predicted using ANFIS and ANFIS-DE (Testing) 
Table 2 Performance evaluation of ANFIS and ANFIS-DE in predicting $F r$ for all models (training and testing)

\begin{tabular}{|c|c|c|c|c|c|c|c|}
\hline & Model No. & Method & $R^{2}$ & RMSE & MAE & MARE & $\delta$ \\
\hline \multirow[t]{12}{*}{ Train } & \multirow[t]{2}{*}{ Model 1} & ANFIS & 0.933 & 0.579 & 0.456 & 0.120 & 0.117 \\
\hline & & ANFIS-DE & 0.972 & 0.370 & 0.285 & 0.074 & 0.073 \\
\hline & \multirow[t]{2}{*}{ Model 2} & ANFIS & 0.707 & 1.136 & 0.876 & 0.260 & 0.224 \\
\hline & & ANFIS-DE & 0.840 & 0.831 & 0.594 & 0.167 & 0.152 \\
\hline & \multirow[t]{2}{*}{ Model 3} & ANFIS & 0.670 & 1.199 & 0.904 & 0.258 & 0.232 \\
\hline & & ANFIS-DE & 0.906 & 0.637 & 0.461 & 0.121 & 0.118 \\
\hline & \multirow[t]{2}{*}{ Model 4} & ANFIS & 0.963 & 0.406 & 0.336 & 0.094 & 0.086 \\
\hline & & ANFIS-DE & 0.973 & 0.341 & 0.272 & 0.072 & 0.070 \\
\hline & \multirow[t]{2}{*}{ Model 5} & ANFIS & 0.798 & 0.960 & 0.716 & 0.188 & 0.183 \\
\hline & & ANFIS-DE & 0.913 & 0.632 & 0.478 & 0.125 & 0.123 \\
\hline & \multirow[t]{2}{*}{ Model 6} & ANFIS & 0.819 & 0.902 & 0.646 & 0.171 & 0.165 \\
\hline & & ANFIS-DE & 0.916 & 0.613 & 0.417 & 0.105 & 0.107 \\
\hline \multirow[t]{12}{*}{ Test } & \multirow[t]{2}{*}{ Model 1} & ANFIS & 0.882 & 0.590 & 0.448 & 0.099 & 0.102 \\
\hline & & ANFIS-DE & 0.963 & 0.392 & 0.331 & 0.076 & 0.075 \\
\hline & \multirow[t]{2}{*}{ Model 2} & ANFIS & 0.611 & 1.375 & 1.103 & 0.240 & 0.252 \\
\hline & & ANFIS-DE & 0.720 & 1.248 & 1.005 & 0.232 & 0.229 \\
\hline & \multirow[t]{2}{*}{ Model 3} & ANFIS & 0.635 & 1.232 & 0.955 & 0.209 & 0.218 \\
\hline & & ANFIS-DE & 0.869 & 0.663 & 0.546 & 0.128 & 0.125 \\
\hline & \multirow[t]{2}{*}{ Model 4} & ANFIS & 0.929 & 0.452 & 0.385 & 0.091 & 0.088 \\
\hline & & ANFIS-DE & 0.965 & 0.323 & 0.281 & 0.065 & 0.064 \\
\hline & \multirow[t]{2}{*}{ Model 5} & ANFIS & 0.735 & 0.866 & 0.749 & 0.185 & 0.171 \\
\hline & & ANFIS-DE & 0.868 & 0.801 & 0.675 & 0.154 & 0.154 \\
\hline & \multirow[t]{2}{*}{ Model 6} & ANFIS & 0.752 & 0.867 & 0.636 & 0.142 & 0.145 \\
\hline & & ANFIS-DE & 0.869 & 0.606 & 0.481 & 0.112 & 0.110 \\
\hline
\end{tabular}

In general, using the $d / D$ parameter as a representative of the sediment group improves $F r$ estimation.

According to the explanations given, in addition to the parameters related to transport $\left(C_{V}\right)$ and flow resistance $\left(\lambda_{s}\right)$ that are constant, using parameter $d / D$ from the sediment group and parameter $d / R$ from transport mode offers the best performance (Model 4). A comparison of ANFIS and ANFIS-DE for all models signifies the superior performance of the hybrid method presented in this study.

Table 3 compares the model presented in this study (ANFIS-DE) with existing regression-based equations using different statistical indicators. According to the table and all indicators, the proposed model produced better results than the regression equations. Among the presented models, most indicators for May et al. (1996) equation indicated better results than Ebtehaj et al. (2014), but the difference is not significant enough to deem one better than another. It is worth noting that May et al. (1996) equation was superior to other equations in terms of MSE, MAE, MARE and $\delta$, and a lower $R^{2}$; therefore, it is quite different from the estimate achieved by May et al. (1996), which increases its unreliability.

Additionally, existing equations were compared with ANFIS-DE in terms of discrepancy ratio $(D R)$, which is equal to the ratio of the predicted value to the actual value. These results are presented in Fig. 5. The $D R$ values for ANFIS-DE, and Ebtehaj et al. (2014) and May et al. (1996) equations are $0.99,1.03$ and 0.97 , respectively. Although

Table 3 Comparison of ANFIS-DE and existing regression-based equations (all data)

\begin{tabular}{|c|c|c|c|c|c|}
\hline Method & $R^{2}$ & RMSE & MAE & MARE & $\delta$ \\
\hline ANFIS-DE & 0.972 & 0.336 & 0.275 & 0.070 & 0.046 \\
\hline May et al. (1996) & 0.916 & 0.574 & 0.358 & 0.080 & 0.055 \\
\hline Ebtehaj et al. (2014) & 0.966 & 0.609 & 0.390 & 0.084 & 0.065 \\
\hline
\end{tabular}


Fig. $5 D R$ values for ANFIS$\mathrm{DE}$ and existing regressionbased equations
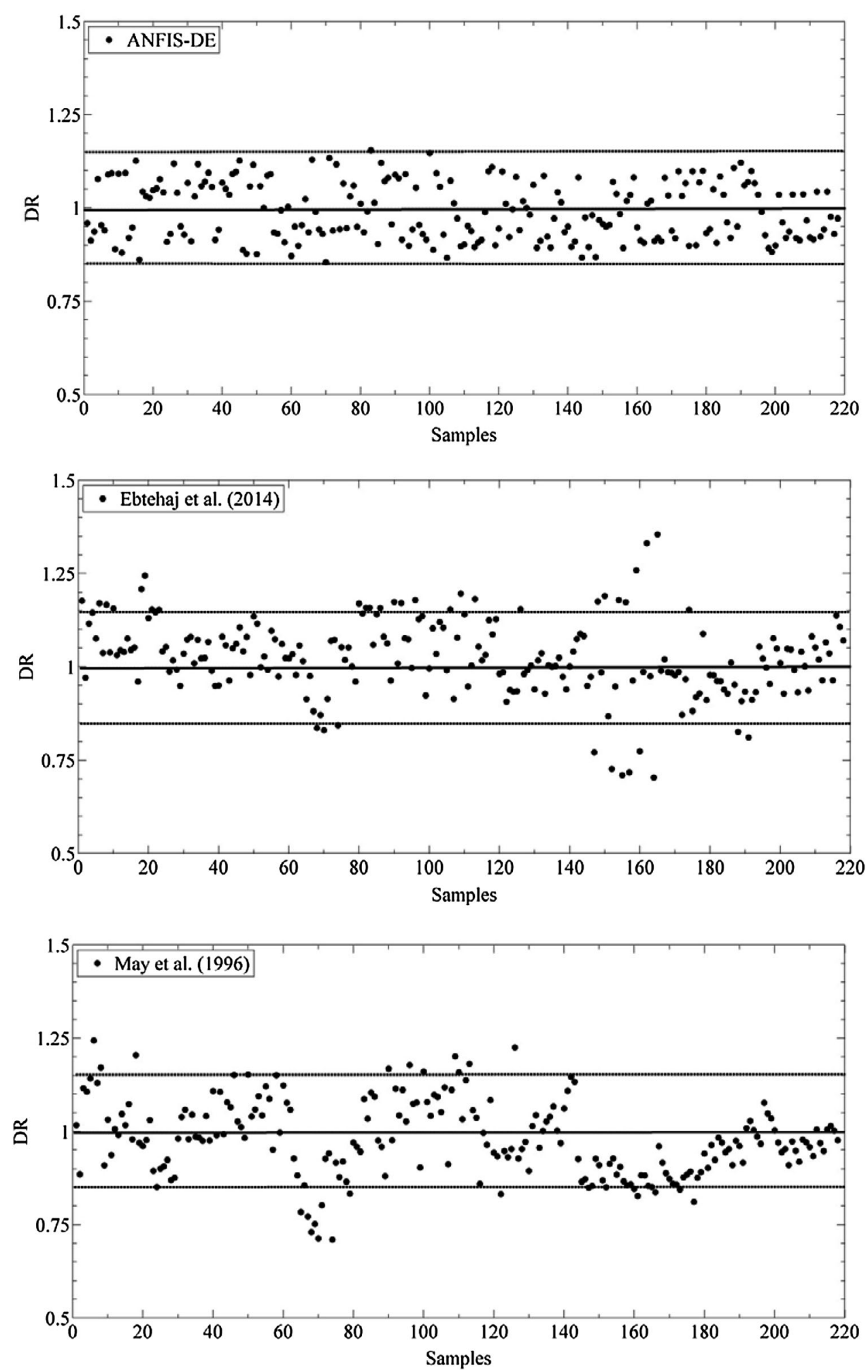

the difference is not vast, model accuracy and the average precision should be confirmed by considering the maximum relative error values as well. In Fig. 5 the $D R$ value for ANFIS-DE is $1 \pm 0.15$, while the estimation results of the two regression equations indicate that some of the estimated values have large error. Thus, overestimation beyond a certain allowance results in non-economical project assessment, while underestimation below a certain value leads to sediment deposition and related problems. Using the equations would also result in less confidence. 


\section{Conclusion}

Sediment transport in pipe channels is a critical subject, because using incorrect designs leads to sediment deposition and non-economical assessments. Therefore, a method that accurately estimates the limiting velocity to prevent sediment deposition is essential. In this study, a hybrid ANFIS was designed based on differential evolution called ANFIS-DE. It was used to predict the densimetric Froude number $(F r)$ parameter, which takes into account the limiting velocity effect. Accordingly, the factors affecting non-deposition sediment transport were determined and the dimensionless parameters were defined to propose six different models (Models 1-6). According to the results obtained for the effect of each dimensionless parameter on the estimated $\mathrm{Fr}$ parameter, using $D^{2} / A$ as a parameter in "transport mode" leads to significantly inferior performance of both methods. The average relative error attained was over $20 \%$ for both methods. The best result of each input combination was achieved by selecting $d / R$ as representative of the "transport mode" group. Besides, by taking into account parameters related to "flow resistance," "transport" and "transport mode," using $D_{\mathrm{gr}}$ instead of $d / D$ led to a minor accuracy reduction of less than $2 \%$. The best performance in estimating the $F r$ parameter was attained by the model that used the following dimensionless parameters: volumetric sediment concentration $\left(C_{V}\right)$, ratio of median particle diameter to hydraulic radius $(d / R)$, ratio of median particle diameter to pipe diameter $(d / D)$ and overall friction factor of sediment $\left(\lambda_{s}\right)(F r=f(C V, d / R, d / D$, $\left.\lambda_{s}\right)$ ). Moreover, a comparison of ANFIS-DE with ANFIS represented the superior performance of ANFIS-DE. Two regression-based methods presented based on semi-experimental and dimensional analysis were also compared with the results of ANFIS-DE. The comparison results indicated the superior performance of ANFIS.

Open Access This article is distributed under the terms of the Creative Commons Attribution 4.0 International License (http:// creativecommons.org/licenses/by/4.0/), which permits unrestricted use, distribution, and reproduction in any medium, provided you give appropriate credit to the original author(s) and the source, provide a link to the Creative Commons license, and indicate if changes were made.

\section{References}

Ab Ghani A (1993) Sediment transport in sewers. Dissertation, University of Newcastle Upon Tyne, UK

Ab Ghani A, Azamathulla HM (2014) Development of GEP-based functional relationship for sediment transport in tropical rivers. Neural Comput Appl 24(2):271-276. doi:10.1007/s00521-012$1222-9$
Ackers JC, Butler D, May RWP (1996) Design of sewers to control sediment problems. Rep. No. CIRIA 141. Construction Industry Research and Information Association, London

Al-Abadi AM (2014) Modeling of stage-discharge relationship for Gharraf River, southern Iraq using backpropagation artificial neural networks, M5 decision trees, and Takagi-Sugeno inference system technique: a comparative study. Appl Water Sci 6(4):407-420. doi:10.1007/s13201-014-0258-7

Almedeij J (2012) Rectangular storm sewer design under equal sediment mobility. Am J Environ Sci 8(4):376-384. doi:10.3844/ ajessp.2012.376.384

Azamathulla HMd, Ab Ghani A, Fei SY (2012) ANFIS-based approach for predicting sediment transport in clean sewer. Appl Soft Comput 12(3):1227-1230. doi:10.1016/j.asoc.2011.12.003

Bäck T, Fogel DB, Michalewicz Z (eds) (1997) Handbook of Evolutionary Computation. Inst. Phys. and Oxford University Press, New York

Banasiak R (2008) Hydraulic performance of sewer pipes with deposited sediments. Water Sci Technol 57:1743-1748. doi:10. 2166/wst.2008.287

Bonakdari H, Ebtehaj I (2014a) Verification of equation for nondeposition sediment transport in flood water canals. In: 7th International Conference on Fluvial Hydraulic RIVER FLOW 2014; Lausanne; Switzerland, 3-5 September, p 1527-1533. doi: $10.1201 / \mathrm{b} 17133-203$

Bonakdari H, Ebtehaj I (2014b) Study of sediment transport using soft computing technique. In: 7th International conference on fluvial hydraulic, RIVER FLOW 2014; Lausanne; Switzerland, 3-5 September, p 933-940. doi:10.1201/b17133-126

Bui DT, Pradhan B, Lofman O, Revhaug I, Dick OB (2012) Landslide susceptibility mapping at Hoa Binh province (Vietnam) using an adaptive neuro-fuzzy inference system and GIS. Comput Geosci 45:199-211. doi:10.1016/j.cageo.2011.10.031

Bui DT, Pradhan B, Nampak H, Bui QT, Tran QA, Nguyen QP (2016a) Hybrid artificial intelligence approach based on neural fuzzy inference model and metaheuristic optimization for flood susceptibilitgy modeling in a high-frequency tropical cyclone area using GIS. J Hydrol 540:317-330. doi:10.1016/j.jhydrol. 2016.06.027

Bui DT, Pham BT, Nguyen QP, Hoang ND (2016b) Spatial prediction of rainfall-induced shallow landslides using hybrid integration approach of Least-Squares Support Vector Machines and differential evolution optimization: a case study in Central Vietnam. Int J Digit Earth 9(11):1077-1097. doi:10.1080/ 17538947.2016.1169561

Bui KTT, Bui DT, Zou J, Van Doan C, Revhaug I (2017a) A novel hybrid artificial intelligent approach based on neural fuzzy inference model and particle swarm optimization for horizontal displacement modeling of hydropower dam. Neural Comput Appl p 1-12. doi:10.1007/s00521-016-2666-0

Bui DT, Bui QT, Nguyen QP, Pradhan B, Nampak H, Trinh PT (2017b) A hybrid artificial intelligence approach using GISbased neural-fuzzy inference system and particle swarm optimization for forest fire susceptibility modeling at a tropical area. Agric For Meteorol 233:32-44. doi:10.1016/j.agrformet.2016. 11.002

Chang JR, Wei LY, Cheng CH (2011) A hybrid ANFIS model based on AR and volatility for TAIEX forecasting. Appl Soft Comput 11(1):1388-1395. doi:10.1016/j.asoc.2010.04.010

Chen MY (2013) A hybrid ANFIS model for business failure prediction utilizing particle swarm optimization and subtractive clustering. Inf Sci 220:180-195. doi:10.1016/j.ins.2011.09.013

Cus F, Balic J, Zuperl U (2009) Hybrid ANFIS-ants system based optimization of turning parameters. J Achiev Mater Manuf Eng 36(1):79-86 
Demirci M, Baltaci A (2013) Prediction of suspended sediment in river using fuzzy logic and multilinear regression approaches. Neural Comput Appl 23(1):145-151. doi:10.1007/s00521-0121280-Z

Ebtehaj I, Bonakdari H (2013) Evaluation of sediment transport in sewer using artificial neural network. Eng Appl Comput Fluid Mech 7(3):382-392. doi:10.1080/19942060.2013.11015479

Ebtehaj I, Bonakdari H (2014a) Performance evaluation of adaptive neural fuzzy inference system for sediment transport in sewers. Water Resour Manag 28(13):4765-4779. doi:10.1007/s11269014-0774-0

Ebtehaj I, Bonakdari H (2014b) Comparison of genetic algorithm and imperialist competitive algorithms in predicting bed load transport in clean pipe. Water Sci Technol 70(10):1695-1701. doi:10.2166/wst.2014.434

Ebtehaj I, Bonakdari H (2016) Assessment of evolutionary algorithms in predicting non-deposition sediment transport. Urban Water $\mathrm{J}$ 5:499-510. doi:10.1080/1573062X.2014.994003

Ebtehaj I, Bonakdari H, Sharifi A (2014) Design criteria for sediment transport in sewers based on self-cleansing concept. J Zhejiang Univ Sci A 15(11):914-924. doi:10.1631/jzus.A1300135

Gholami R, Kamkar-Rouhani A, Ardejani FD, Maleki S (2011) Prediction of toxic metals concentration using artificial intelligence techniques. Appl Water Sci 1(3-4):125-134. doi:10.1007/ s13201-011-0016-Z

Gorai AK, Hasni SA, Iqbal J (2014) Prediction of ground water quality index to assess suitability for drinking purposes using fuzzy rule-based approach. Appl Water Sci. doi:10.1007/s13201014-0241-3

Ivanovich EV, Hamid K (2014) An alternative approach for assessing sediment impact on aquatic ecosystems using single decision tree (SDT). J Water Sustain 4(3):181-204. doi:10.11912/jws. 2014.4.3.181-204

Jang JSR, Sun CT, Mizutani E (1997) Neurofuzzy and soft computing: a computational approach to learning and machine intelligence. Prentice-Hall, New Jersey

Liu J, Lampinen J (2002) On setting the control parameter of the differential evolution method. In: Proc. 8th Int. Conf. Soft Computing (MENDEL 2002), p 11-18

MATLAB and Statistics Toolbox Release (2009) Fuzzy logic toolboxTM user's guide. The MathWorks Inc., Natick, Massachusetts
May RWP (2003) Preventing sediment deposition in inverted sewer siphons. J Hydraul Eng 129(4):283-290. doi:10.1061/ (ASCE)0733-9429(2003)129:4(283)

May RWP, Ackers JC, Butler D, John S (1996) Development of design methodology for self-cleansing sewers. Water Sci Technol 33(9):195-205. doi:10.1016/0273-1223(96)00387-3

Mayerle R, Nalluri C, Novak P (1991) Sediment transport in rigid bed conveyance. J Hydraul Eng 29(4):475-495. doi:10.1061/ (ASCE)1084-0699(2007)12:5(532)

Mondal NK, Bhaumik R, Das B, Roy P, Datta JK, Bhattacharyya S, Bhattacharjee S (2015) Neural network model and isotherm study for removal of phenol from aqueous solution by orange peel ash. Appl Water Sci 5(3):271-282. doi:10.1007/s13201014-0188-4

Moosavi V, Vafakhah M, Shirmohammadi B, Behnia N (2013) A wavelet-ANFIS hybrid model for groundwater level forecasting for different prediction periods. Water Resour Manag 27(5):1301-1321. doi:10.1007/s11269-012-0239-2

Nalluri C, Ab Ghani A (1996) Design option for self-cleansing storm sewers. Water Sci Technol 33(9):215-220. doi:10.1016/02731223(96)00389-7

Ota JJ, Nalluri C (1999) Graded sediment transport at limit deposition in clean pipe channel. In: 28th international association for hydro-environment engineering and research, Graz, Austria

Shoorehdeli MA, Teshnehlab M, Sedigh AK (2007) Novel hybrid learning algorithms for tuning ANFIS parameters using adaptive weighted PSO. In: Fuzzy Systems Conference, 2007. FUZZIEEE 2007. IEEE International (pp. 1-6). IEEE. doi: 10.1109/ FUZZY.2007.4295571

Shoorehdeli MA, Teshnehlab M, Sedigh AK, Khanesar MA (2009) Identification using ANFIS with intelligent hybrid stable learning algorithm approaches and stability analysis of training methods. Appl Soft Comput 9(2):833-850. doi:10.1016/j.asoc.2008.11. 001

Storn R, Price K (1997) Differential evolution-A simple and efficient heuristic for global optimization over continuous spaces. J Global Optim 11:341-359. doi:10.1023/A: 1008202821328

Vongvisessomjai N, Tingsanchali T, Babel MS (2010) Non-deposition design criteria for sewers with part-full flow. Urban Water J 7(1):61-77. doi:10.1080/15730620903242824 